\title{
RUBELLA OUTBREAK AMONG TRAINEES OF NATIONAL SERVICE PROGRAM IN PASIR MAS, KELANTAN, MALAYSIA
}

\author{
Hasniza Abdullah ${ }^{1}$, Mohammad Saffree Jeffree ${ }^{2}$, Azman Atili2,4, Syed Sharizman Syed Abdul Rahim², Mohd \\ Rohaizat Hassan ${ }^{4}$, Khamisah Awang Lukman ${ }^{2}$ and Kamrudin Ahmed ${ }^{3}$
}

\begin{abstract}
${ }^{1}$ Pasir Mas District Health Office Kelantan, Jalan Hospital Lati, 17000 Pasir Mas, Kelantan
${ }^{2}$ Department of Community and Family Medicine, Faculty of Medicine and Health Sciences, Universiti Malaysia Sabah, 88400 Kota Kinabalu, Sabah, Malaysia.

${ }^{3}$ Borneo Medical and Health Research Centre, Faculty of Medicine and Health Sciences, Universiti Malaysia Sabah, 88400 Kota Kinabalu, Sabah, Malaysia.

${ }^{4}$ Department of Community Health, Faculty of Medicine, National University of Malaysia, 56000 Bandar Tun Razak, Kuala Lumpur, Malaysia.
\end{abstract}

Corresponding author: Mohammad Saffree Jeffree

Email: saffree@ums.edu.my

\begin{abstract}
An outbreak occurred at the National Service Training Camp Cancun Park in Pasir Mas, Kelantan and subsequent outbreak investigation was carried out to verify the agent of the outbreak and to recommend a control measure. Descriptive (cases series) study was carried from $13^{\text {th }}$ April 2008 to $16^{\text {th }}$ May 2008 at the training camp. The case definition for the outbreak was a person presenting with a maculopapular rash with or without fever from $1^{\text {st }}$ April 2008 and stayed in the training camp. Confirmed cases were clinical cases positive for rubella IgM. Case findings were carried out by the medical team in the camp and from the nearest health center where the affected person who fit in the clinical case definition were interviewed, clinically examined, and had blood investigations done. A total of 337 persons (280 trainees and 57 camp trainers) occupied the training center at the point of outbreak were purposively included in this study. Out of 337 occupants of the training camp, 22 (6.5\% attack rate) fulfilled the case definition and all of them were among trainees. $95 \%$ of cases were male and $86 \%$ were Malays. $100 \%$ had maculopapular rash, $77 \%$ presented with fever, $41 \%$ presented with cough and $50 \%$ presented with conjunctivitis. Rubella-specific IgM antibody was positive in $59 \%(n=13)$ of the cases. There was no history of vaccination for all the confirmed cases. Control measures taken were strict isolation of the affected trainees, daily surveillance of rash and fever, and health education to promote awareness on symptoms and signs, nature of transmission, prevention, and control of rubella infection to trainees. Rubella is confirmed as the cause of the outbreak based on the clinical and serological analysis. The probable source of the outbreak is the possibility of exposure during a family day at the training camp.
\end{abstract}

Keywords: Rubella, Outbreak, Maculopapular rash, Vaccine preventable disease

\section{INTRODUCTION}

Although acquired rubella is usually a benign disease of children and young adults, it is highly teratogenic ${ }^{1}$. The real threat arises when rubella virus infects the fetus, particularly during the first trimester, when infection can lead to miscarriage or congenital rubella syndrome ${ }^{2}$. WHO passed unanimously a resolution that urged that all Member States in the WPRO Region to aim to eliminate rubella as soon as possible ${ }^{1}$. In 2002, Malaysia adapted Universal Rubella Vaccination Program as part of the childhood Measles, Mumps, and Rubella (MMR) vaccination strategy ${ }^{3}$. Since rubella is not a notifiable disease, the disease burden and outbreak report are scarce in Malaysia ${ }^{3}$. The National Service Program was introduced by the Malaysian government to enhance unity among the multi-racial communities in the country, to instill a spirit of caring and volunteerism among society, to produce an active, intelligent and confident generation and to develop positive characteristics among the younger generation through good values ${ }^{4}$. The National Service Training Camp Cancun Park in Pasir Mas, Kelantan is one of the training camps that were set up in 2004 for those secondary 5 school leavers. Selected trainees are trained in the camp for 3 months in 3 badges each year according to the training module aimed at fostering unity among the Malaysian citizens ${ }^{4}$. On $4^{\text {th }}$ May 2008, three trainees were presented with fever and rash and were referred to Pasir Mas Health Centre from the training center. A total of 337 persons (280 trainees and 57 camp trainers) occupied the training center at the point of outbreak. Therefore, the aim of this study is to determine the agent responsible for the outbreak and it is hoped that the findings will be useful for policymakers for future prevention of the disease.

\section{METHODS}

Descriptive (cases series) study was carried from $13^{\text {th }}$ April 2008 to $16^{\text {th }}$ May 2008 at the training camp. The case definition was a person presented with maculopapular rash with or without fever from $1^{\text {st }}$ April 2008 and stayed in the training camp. Confirmed cases were clinical cases positive for rubella lgM. The case findings were done through active case detection (ACD) immediately upon receiving the notification on $4^{\text {th }}$ 
May 2008. All trainees and camp trainers were assembled at the camp dining hall and attendance were checked according to the trainees list obtained from management of the training camp. The health team from the district health office interviewed the cases and the information on patient's identification such as name and dormitory, demographic details such as age, gender, ethnicity, clinical sign and symptoms, date of onset, and laboratory findings were gathered. Passive case detection (PCD) and symptomatic treatment were done by the medical team of the training camp as well as in Pasir Mas Health Centre. The vaccination status of the trainee was obtained through questionnaires. All the 337 training camps occupants were purposively included in the study. An amount of 5 $\mathrm{ml}$ blood samples was obtained from each of the affected person on the $4^{\text {th }}$ May 2008. Consent for serological tests was granted by participants and administration. Rubella-specific IgM was tested using the Axsym Automated Analyzer (Abbot Laboratories, Abbott Park, IL). For IgM serology for measles and rubella, ELISA method was used. There were eight classrooms that are used for activities and are used on sharing basis.

\section{RESULTS}

Of the 337 samples, 22 (6.5\% attack rate) fulfilled the case definition and all of them were among trainees. All the affected trainees were 18 years old, $95 \%$ were male and $86 \%$ were Malays (Table 1). None of them required hospital admission and they were all treated as outpatient. The IgM result for measles was negative in all cases but positive for rubella in $13(59 \%)$ of the cases. None of the patients were vaccinated for rubella. The dates and time of onset of illness for all the 22 cases are shown in Figure 1. The epidemic curve illustrates a common source of infection. The first case occurred on $14^{\text {th }}$ April 2008 involving an 18 years old boy who lived in the Akasia dormitory. He did not have any contact with anyone with similar manifestations prior to his illness. The peak of infection occurred on $30^{\text {th }}$ April 2008 and followed by new cases on $2^{\text {nd }}-3^{\text {rd }}$ May 2008 . The outbreak ended on $16^{\text {th }}$ May 2008 . The main symptoms were maculopapular rash (100\%) (Figure 2), fever and/or history of fever (77\%), conjunctivitis $(50 \%)$ and cough $(41 \%)$ as in Table 1 . Some of the reported cases presented with maculopapular rash after the second day of fever. None of the cases had a history of rashes after the third day of fever and none of them had neck or posterior lymphadenopathy. The size of each dormitory was 2,420 square meters and housed 25-30 students. Ventilation was good with adequate windows and eight electric fans are available in each dorm. General hygiene of the dormitories, toilets, and surrounding areas were satisfactory.

Table 1: Characteristic of cases fulfilled the case definition $(\mathrm{N}=22)$

\begin{tabular}{lcc}
\hline \multicolumn{1}{c}{ Variable } & Frequency $(\mathbf{n})$ & Percentage $(\%)$ \\
\hline Age (18 years old) & 22 & 100 \\
Gender & 21 & 95 \\
$\quad$ Male & 1 & 5 \\
$\quad$ Female & 19 & 86 \\
Ethnic & 3 & 14 \\
$\quad$ Malay & & \\
$\quad$ Chinese & 22 & 100 \\
Symptoms & 17 & 77 \\
$\quad$ Maculopapular rash & 11 & 50 \\
$\quad$ Fever & 9 & 41 \\
$\quad$ Conjunctivitis & & \\
$\quad$ Cough & 13 & 59 \\
Rubella-specific lgM antibody & 9 & 41 \\
$\quad$ Positive & & \\
$\quad$ Negative &
\end{tabular}


$1^{\text {st Notification received }}$

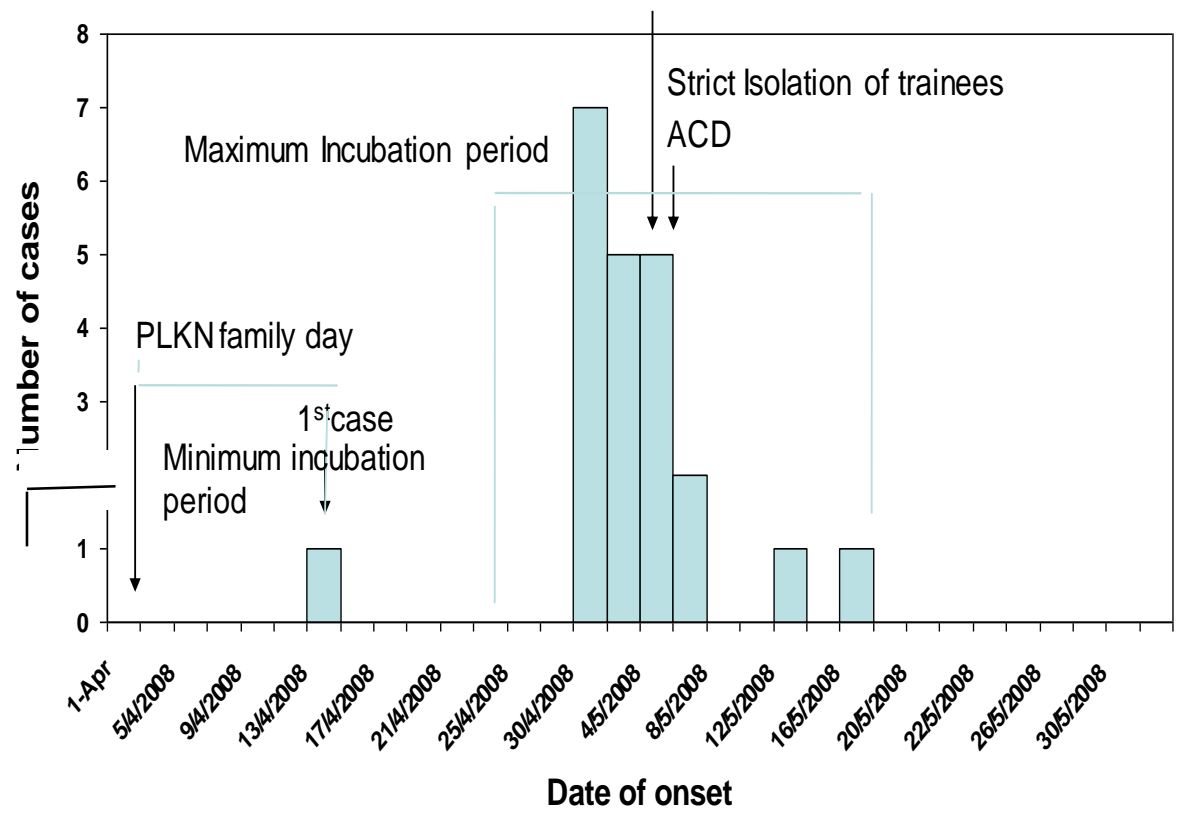

Onset dates were collapsed every 2 days

Figure 1: Epidemic Curve of Rubella Outbreak

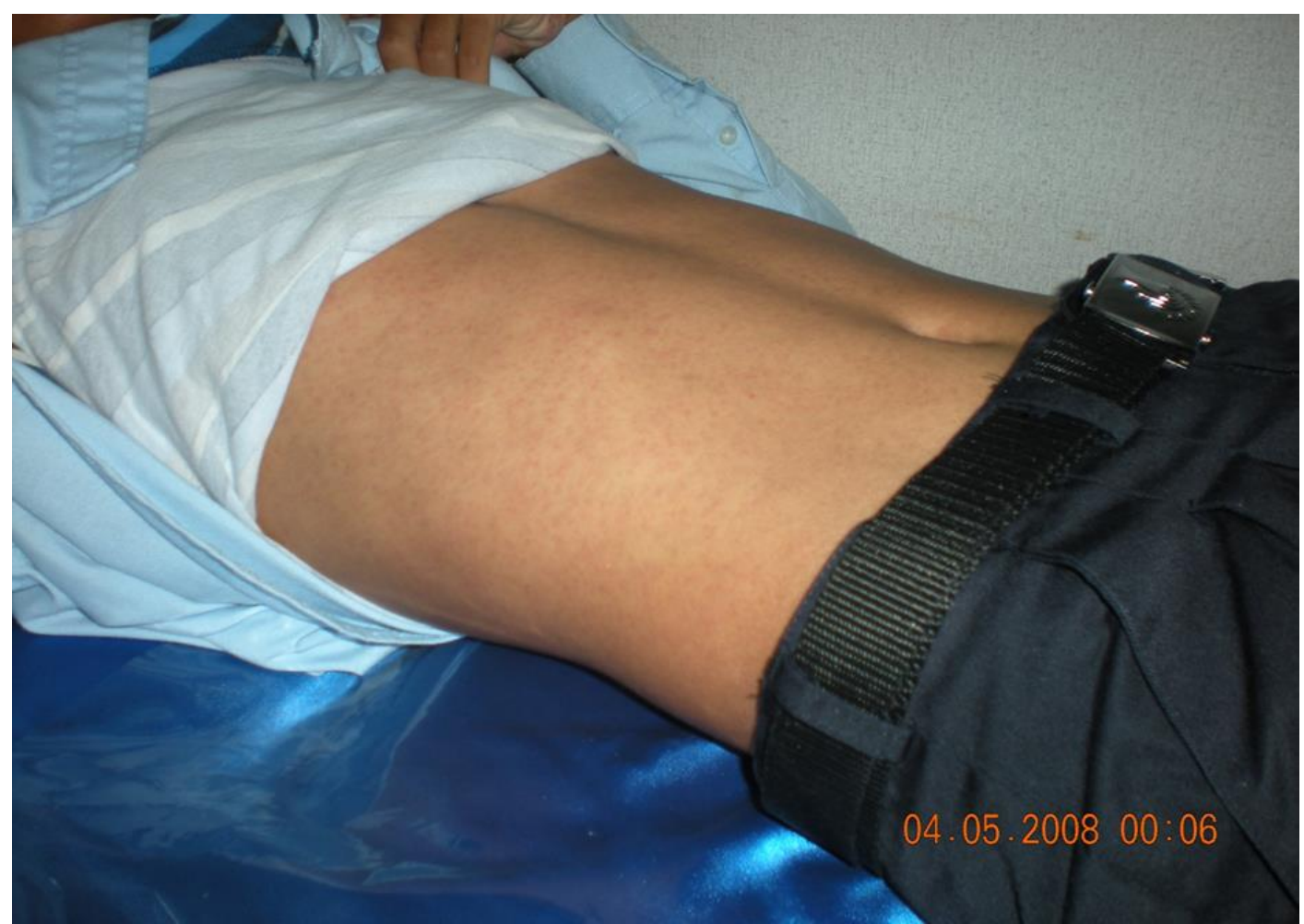

Figure 2: Maculopapular skin rash on the abdomen 


\section{DISCUSSION}

Although most cases of rubella are mild, selflimited diseases associated with characteristic rash remains an important pathogen of public health concern worldwide ${ }^{2}$. For example, the rubella epidemic in Japan recorded more than 15,000 cases of rubella and 43 cases of congenital rubella syndrome during 2012-20145.

The outbreak in the training camp in Pasir Mas, Kelantan was a common cause outbreak. It was a small outbreak that lasted for 16 days. In this situation, there was a potential for extensive spread of rubella in a short duration of time because of the large population in closed communities. The prominent maculopapular rash with fever, conjunctivitis, and cough observed in patients could be easily and often misdiagnosed as measles especially among doctors with nonextensive experience ${ }^{3}$.

Although rubella is asymptomatic in $25 \%-50 \%$ of cases, the rash characteristically begins on the face and spreads to the trunk and extremities ${ }^{6}$. None of our cases had a history of rashes after the third day of fever. This was consistent with findings in other studies that found that acute measles illness can be differentiated with rubella where skin eruption only starts to appear after three days of fever ${ }^{3}$. In contrary to other outbreaks, neck lymphadenopathy was not observed in this study ${ }^{7}$. Except for one female patient, all other patients were male in the present outbreak. In 1987, the monovalent rubella vaccine was incorporated in the national vaccination program, and only schoolgirls were given immunization ${ }^{8}$. With selective vaccination strategy, young boys were not the target group and remained as potential sources of infection. Because of this selective vaccination strategy, rubella outbreak in Poland and Romania affected the males ${ }^{9,10}$. In 2002, the Measles, Mumps and Rubella (MMR) vaccine was included in the national vaccination program. All young boys and girls were vaccinated and the coverage rate for MMR in Malaysia has been above $85 \%{ }^{11}$.

In this study, the female patient was not vaccinated for rubella. Since the primary case did not have any history of contact with anyone with a similar illness, based on the epidemic curve and incubation period of rubella, the most possible source of the outbreak is the exposure of the primary case during a family day event at the training camp on $1^{\text {st }}$ April 2008. Acquired rubella is transmitted via airborne droplet emission from the upper respiratory tract of active cases ${ }^{12}$. This has further explained how easily the transmission can occur through the closed physical activities conducted during the family day event. As there is no carrier state and the reservoir exists entirely in active human cases $^{2}$, there could be a sick person participated in the event. The virus has an incubation period of two to three weeks and the disease is most contagious when the rash is erupting, but the virus may shed from seven days before rash onset and five to seven days or more after rash onset ${ }^{10}$. This explained the probability of the sick person not featuring any symptoms during the event and goes undetected. Although rubella transmission is usually associated with repeated exposure, transmission has been documented after a single exposure ${ }^{2}$. Thus, the likelihood of the family event as the source of outbreak was justified. This study revealed higher number of cases reported among male trainees in the Akasia dormitory which recorded $55 \%(n=12)$ of cases were IgM positive. Rubella specific IgM is present in only about $50 \%(n=11)$ of rubella cases on the day of rash, but five days after rash, most rubella cases have detectable rubella specific $\lg M^{2}$. If negative result is obtained from a sample taken before four to five days after rash onset, another sample should be taken as soon as possible thereafter ${ }^{13}$. However, in our study we were not able to repeat the blood sampling due to budget constraints.

\section{CONCLUSION}

Rubella was confirmed as the cause of outbreak based on the clinical and serological analysis, and this outbreak was classified as a common source outbreak. The most probable source of the outbreak was the possibility of exposure during the family day at the training camp. We recommend limited traveling by avoiding the trainees from using public transport to go home, and risk communication to management of training camp and trainees.

\section{Conflict of interest}

The authors declare no potential conflict of interest.

\section{Acknowledgements}

The authors would like to express our deepest gratitude and thanks to the Director of Epidemic Intelligence Program (EIP) Malaysia, EIP Supervisor, Deputy Director of Public Health Kelantan, Medical Officer of Health Pasir Mas, Camp Commander Training Center Park and Staff of Pasir Mas District Health Office.

\section{REFERENCES}

1. Su Q, Ma C, Wen N, Fan C, Yang H, Wang $H$, Yin $Z$, Feng $Z$, Hao L, Yang $W$. Epidemiological profile and progress toward rubella elimination in China. 10 years after nationwide introduction of rubella vaccine. Vaccine. 2018 Apr 12;36(16):2079-85.

2. Lambert $N$, Strebel $P$, Orenstein $W$, Icenogle J, Poland GA. Rubella. The Lancet. 2015 Jun 6;385(9984):2297-307. 
3. Yusof, A. M., Selvanesan, S., Norizah, I., Zuridah, H., Kumarasamy, V., Mariam, M., \& Chua, K. B. 2006. Rubella outbreak amongst residential students in a military vocational school of Malaysia. Medical journal of Malaysia, 61(3), 296.

4. Abd Manaf N, Samah BA, Ahmad N. The Impact of the National Service Programme on Self-resilience Among Youth in Malaysia. VOL. 21 (S) JUL. 2013. 2013 Jul $1: 59$.

5. Ujiie M, Nabae K, Shobayashi T. Rubella outbreak in Japan. The Lancet. $2014 \mathrm{Apr}$ 26;383(9927):1460-1.

6. Mehta, S., Rajaram, S., \& Goel, N. (2011). Advances in Obstetrics and Gynecology (Vol. 3) (Vol. 3). JP Medical Ltd.

7. Suleiman, A., Ariffin, R., Kamaludin, F., Arifin, R. M., Kamaluddin, A., Ngadiman, S., \& Ujang, N. 2016. Rubella outbreak in a boarding school, Malaysia, April 2007. OSIR Journal, 3(2), 12-16.

8. Narimah, A., Rubella immunization in Malaysia--20 years on, and the challenges ahead. Med J Malaysia, 2005. 60(3): p. 267-8.

9. Paradowska-Stankiewicz I, Czarkowski MP, Derrough T, Stefanoff P. Ongoing outbreak of rubella among young male adults in Poland: increased risk of congenital rubella infections. Eurosurveillance. $2013 \quad$ May 23;18(21):20485.

10. Banatvala JE, Brown DW. Rubella. The Lancet. 2004 Apr 3;363(9415):1127-37.

11. Saraswathy TS, Zahrin HN, Norhashmimi $\mathrm{H}$, Az-Ulhusna A, Zainah S, Rohani J. Impact of a measles elimination strategy on measles incidence in Malaysia. Southeast Asian journal of tropical medicine and public health. 2009 Jul $1 ; 40(4): 742$.

12. Saraswathy TS, Rozainanee MZ, Asshikin RN, Zainah S. Congenital rubella syndrome: a review of laboratory data from 2002 to 2011. Southeast Asian J Trop Med Public

13. Cutts FT, Robertson SE, Diaz-Ortega JL, Samuel R. Control of rubella and congenital rubella syndrome (CRS) in developing countries, Part 1: Burden of disease from CRS. Bulletin of the World Health Organization. 1997;75(1):55. 